\title{
Estimation of the relationship between remotely sensed anthropogenic heat discharge and building energy use
}

\author{
Yuyu Zhou ${ }^{\mathrm{a}, *}$, Qihao Weng ${ }^{\mathrm{b}}$, Kevin R. Gurney ${ }^{\mathrm{c}}$, Yanmin Shuai ${ }^{\mathrm{d}, \mathrm{e}}$, Xuefei Hu ${ }^{\mathrm{f}}$ \\ a Joint Global Change Research Institute, Pacific Northwest National Laboratory, 5825 University Research Court, Suite 3500, College Park, MD 20740, USA \\ ${ }^{\mathrm{b}}$ Center for Urban and Environmental Change, Department of Earth and Environmental Systems, Indiana State University, Terre Haute, IN 47809, USA \\ ' School of Life Sciences, Arizona State University, P.O. Box 874501, Tempe, AZ 85287-4501, USA \\ d Earth Resources Technology Inc., Laurel, MD 20707, USA \\ ${ }^{\mathrm{e}}$ NASA Goddard Space Flight Center, Greenbelt, MD 20771, USA \\ ${ }^{\mathrm{f}}$ Rollins School of Public Health, Emory University, Atlanta, GA 30322, USA
}

\section{A R T I C L E I N F O}

\section{Article history:}

Received 30 May 2011

Received in revised form 19 August 2011

Accepted 17 October 2011

Available online $\mathrm{xxxx}$

\section{Keywords:}

Anthropogenic heat discharge

Building energy use

Multi-scale

Urban heat island

Urban remote sensing

\begin{abstract}
A B S T R A C T
This paper examined the relationship between remotely sensed anthropogenic heat discharge and energy use from residential and commercial buildings across multiple scales in the city of Indianapolis, Indiana USA. The anthropogenic heat discharge was estimated with a remote sensing-based surface energy balance model, which was parameterized using land cover, land surface temperature, albedo, and meteorological data. The building energy use was estimated using a GIS-based building energy simulation model in conjunction with Department of Energy/Energy Information Administration survey data, the Assessor's parcel data, GIS floor areas data, and remote sensing-derived building height data. The spatial patterns of anthropogenic heat discharge and energy use from residential and commercial buildings were analyzed and compared. Quantitative relationships were evaluated across multiple scales from pixel aggregation to census block. The results indicate that anthropogenic heat discharge is consistent with building energy use in terms of the spatial pattern, and that building energy use accounts for a significant fraction of anthropogenic heat discharge. The research also implies that the relationship between anthropogenic heat discharge and building energy use is scale-dependent. The simultaneous estimation of anthropogenic heat discharge and building energy use via two independent methods improves the understanding of the surface energy balance in an urban landscape. The anthropogenic heat discharge derived from remote sensing and meteorological data may be able to serve as a spatial distribution proxy for spatially-resolved building energy use, and even for fossil-fuel $\mathrm{CO}_{2}$ emissions if additional factors are considered.

(c) 2011 International Society for Photogrammetry and Remote Sensing, Inc. (ISPRS) All rights reserved.
\end{abstract}

\section{Introduction}

The urban heat island (UHI) phenomenon is formed when higher atmospheric and surface temperatures in urbanized areas are observed over the surrounding rural areas (Voogt and Oke, 2003). Based on the surface energy balance theory, UHI is mainly caused by the combination of anthropogenic heat discharge due to energy consumption, increased impervious surface area, and decreased vegetation and water area (Kato and Yamaguchi, 2005). Human induced energy discharge has an important impact on the urban environment in terms of the surface energy balance. Quantification of each heat flux in the energy balance, especially the human induced anthropogenic heat discharge and its spatial pattern, is important to improve the understanding of human im-

\footnotetext{
* Corresponding author. Tel.: +1 4017891497

E-mail address: zhouyuyu@gmail.com (Y. Zhou).
}

pacts on the urban environment, a key issue in global environmental change.

The methods used to estimate anthropogenic heat discharge can be grouped into three major categories: inventory approaches, micrometeorologically-based energy budget closure methods, and building energy modeling approaches (Sailor, 2011). For example, using a inventory approach Lee et al. estimated anthropogenic heat emissions in the Gyeong-In region of Korea in 2002 based on the energy consumption statistics data (Lee et al., 2009). Kato and Yamaguchi separated the contribution of anthropogenic heat discharge and heat radiation due to solar input to the sensible heat flux by using an energy balance method (Kato and Yamaguchi, 2005). Heiple and Sailor (2008) estimated the hourly energy consumption from residential and commercial buildings at $100 \mathrm{~m}$ spatial resolution in Houston, Texas using the building energy modeling method. Each of these methods has its strengths and limitations. Estimation of anthropogenic heat emissions using the inventory approach is 
based on the real energy consumption data at the spatial scale of utility service territories (Ichinose et al., 1999; Klysik, 1996; Lee et al., 2009; Sailor and Lu, 2004; Taha, 1997). It is difficult to quantify the spatial distribution of energy consumption at fine spatial and temporal scales. Spatial and temporal downscaling can only be achieved when additional data such as land use are employed. Energy balance method has been applied to estimate energy fluxes in urban areas from site and neighborhood scale to city scale (Belan et al., 2009; Masson et al., 2002; Oke, 1988; Oke et al., 1999; Pigeon et al., 2007; Pigeon et al., 2008). High spatial resolution anthropogenic heat discharge can be estimated based on micrometeorologically-based energy budget closure method by the combined use of remote sensing and meteorological data (Bastiaanssen et al., 1998a,b; French et al., 2005; Kato and Yamaguchi, 2005; Kato et al., 2008; Schmugge et al., 1998; van der Kwast et al., 2009). However, as the estimation of anthropogenic heat discharge is based on the residual of other components in the surface energy balance, each component introduces uncertainties and propagates errors toward the final estimated anthropogenic heat flux. By integrating the geospatial data and simulated temporal pattern of energy consumption for representative buildings, energy consumption in all buildings can be estimated using the building energy modeling method (Heiple and Sailor, 2008; Ichinose et al., 1999; Zhou and Gurney, 2010). However, the representative buildings may not be easily categorized and the use of representative buildings may introduce bias in the estimation of spatial and temporal patterns of energy use for some buildings as these buildings may have different behaviors of energy consumption in terms of magnitude and temporal pattern compared to the representative buildings.

Although anthropogenic heat discharge was studied using different methods in previous studies, there was limited research for cross-examination of the spatial pattern of anthropogenic heat discharge. Even though previous studies have provided insights into the human impacts on the urban environment directly or indirectly, simultaneous estimation of anthropogenic heat discharge using multiple methods will help to reduce the uncertainties in the study of urban heat fluxes and improve the understanding of the role of human activities in the surface energy balance and its contribution to UHI. This study aims to improve the understanding of the urban surface energy balance and clarify the spatial pattern of energy related human activities with the help of remote sensing data, technologies and building energy simulation in a highly urbanized area. Specifically, anthropogenic heat discharge and energy use from residential and commercial buildings were investigated using two different methods in the metropolitan Indianapolis, Indiana region. First, anthropogenic heat discharge was estimated using a surface energy balance method. Then energy use from residential and commercial buildings was calculated using a building energy modeling method. Finally, the relationship between remotely sensed anthropogenic heat discharge and building energy use was examined across multiple scales from pixel aggregations to census block groups.

\section{Study area and datasets}

\subsection{Study area}

In this study, Indianapolis/Marion County, Indiana was chosen as the experiment area (Fig. 1). Indianapolis is the capital of the State of Indiana, and was listed as the 14th largest city in the USA in 2008, with a population of 798,382 (US Census Bureau, 2009). The city has a temperate climate without pronounced wet or dry seasons, but has obvious seasonal changes. The total annual heating degree day value is $5521 \mathrm{~F}$, and the cooling degree day value is $1042 \mathrm{~F}$ (National Weather Service, 2002). The synoptic weather condition during the study period is typical of mid-latitude summer time. The city of Indianapolis lies on the White River at its confluence with

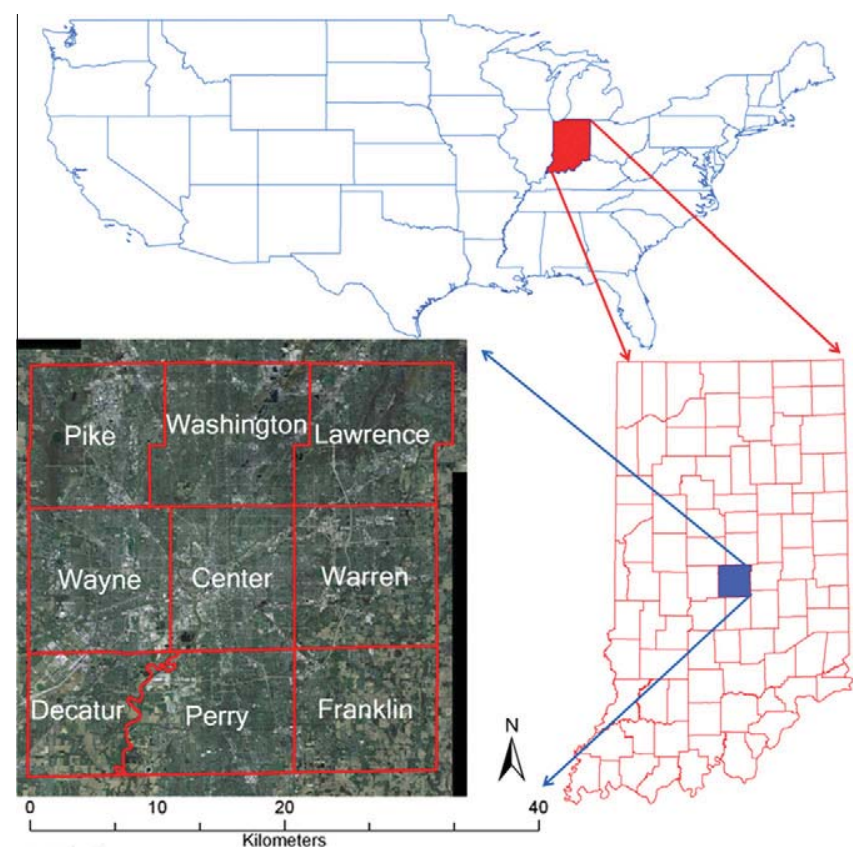

Fig. 1. The study area of Indianapolis City, Marion County, Indiana, USA.

Fall Creek, near the center of the state. It presently extends into nine Marion County Townships, including Pike, Washington, Lawrence, Wayne, Center, Warren, Decatur, Perry and Franklin. The city is located on a flat plain and is relatively symmetrical, having possibilities of expansion in all directions, and the city center has expanded into adjacent agricultural and rural lands through encroachment (Weng and $\mathrm{Hu}, 2008$ ). Indianapolis is a highly urbanized city with spatially heterogeneous human activities, which serves as an ideal area for the purpose of this study.

\subsection{Datasets}

Anthropogenic heat discharge at noon time on June 16th, 2001 (Saturday) was estimated using a surface energy balance modeling approach (Fig. 2). The details of the approach were discussed in the methodology section. The major data used in the energy balance method include meteorological data, land cover, albedo and land surface temperature (LST). Impervious surface area (ISA) was also developed and utilized as a mask in the analysis. Meteorological data including air temperature, shortwave radiation, and wind speed at noon time on June 16th, 2001 were retrieved from 3hourly MAT3FXCHM data product at the Modeling and Assimilation Data and Information Services Center (http://disc.sci.gsfc.nasa.gov/ MDISC/). The data processing of land cover, albedo, LST and ISA is discussed below in details.

Land cover data from US Geological Survey National Land Cover Dataset (NLCD) 2001 were collected to retrieve parameters for the estimation of surface heat fluxes (Fig. 3a). The land cover classification was achieved by using a classification and decision tree method with Landsat imagery and ancillary data (Homer et al., 2004). Main land cover types in the study area include open water, urban, evergreen forest, deciduous forest, shrub, grassland, cropland and wetland. Urban is the dominant land use in Indianapolis and accounts for more than $3 / 4$ of the total area. This dataset was utilized to create a look up table between land cover type and modeling parameters, including coefficient for ground heat flux, roughness length and emissivity, which were developed in previous studies (Kato and Yamaguchi, 2005; Kato et al., 2008; Snyder et al., 1998). Land cover based parameters used in the estimation of heat fluxes will be further discussed in the methodology section. 


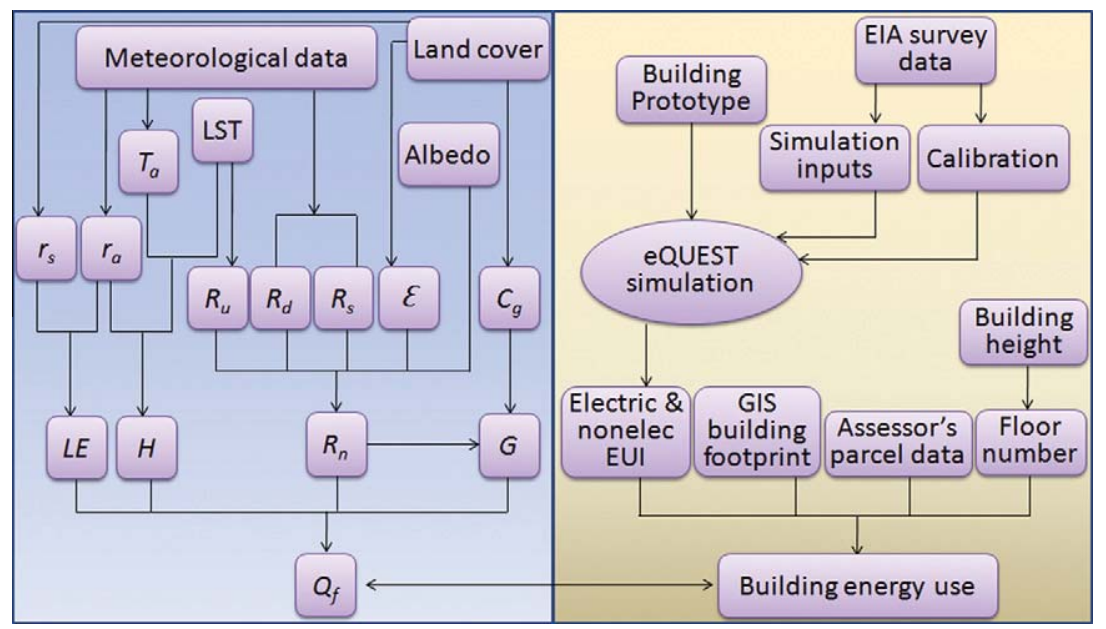

Fig. 2. Methodology used to estimate anthropogenic heat discharge and energy use from residential and commercial buildings.
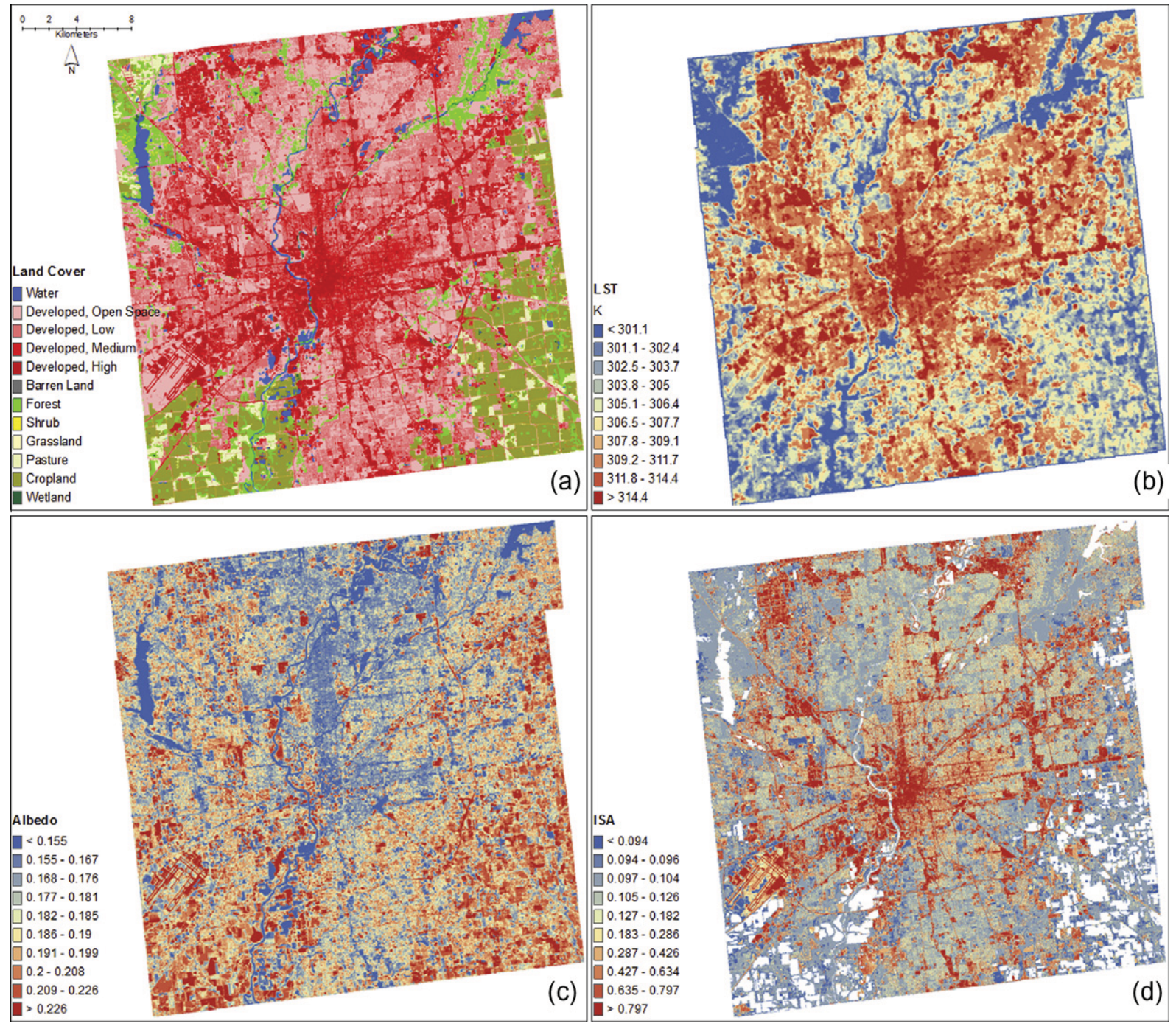

Fig. 3. Model input data in the study area of Indianapolis including land cover (a), LST (b), albedo (c), and ISA (d).

The advanced spaceborne thermal emission and reflection radiometer (ASTER) on-demand L2 surface kinetic temperature data with $90 \mathrm{~m}$ resolution of June 16th, 2001 were purchased from
NASA (Fig. 3b). The algorithm for converting ASTER thermal infrared measurements to LSTs has been reported by the ASTER temperature/emissivity working group (Gillespie et al., 1999), with which 
surface kinetic temperature was determined by applying Planck's Law using the emissivity values from the temperature-emissivity separation (TES) algorithm. LST values calculated using this procedure are expected to have an absolute accuracy of 1-4 K and relative accuracy of $0.3 \mathrm{~K}$, and surface emissivity values are expected to have an absolute accuracy of $0.05-0.1$ and relative accuracy of 0.005 (Gillespie et al., 1999).

Land surface albedo map in $30 \mathrm{~m}$ spatial resolution was generated from Landsat surface reflectance and anisotropy information based on concurrent moderate resolution imaging spectroradiometer (MODIS) $500 \mathrm{~m}$ observations through the algorithm developed by Shuai et al. (2011) (Fig. 3c). The level 1 Landsat 7 enhanced thematic mapper plus (ETM+) image collected on July 11th, 2001 with good quality was first converted to $30 \mathrm{~m}$ land surface reflectance through Landsat ecosystem disturbance adaptive processing system, an automatic calibration and atmospheric correction process (Masek et al., 2006). Then the classification-based $500 \mathrm{~m}$ Bidirectional reflectance distribution function (BRDFs) for the homogenous area were extracted from the concurrent MODIS BRDF product (Schaaf et al., 2002) with the highest inversion quality (Shuai et al., 2008), followed by the calculation of spectral albedo-to-reflectance ratios for each class at the MODIS pixel scale. Next, the spectral Landsat albedos were inversed by applying these ratios into Landsat surface reflectance. According to the validation with ground measurements, the Landsat albedo meets the accuracy required by regional climate modeling. Compared with the MODIS 500 m products, it also provides a detailed landscape texture and improved accuracy at the validation stations (Shuai et al., 2011). It was assumed that there was no significant change of albedo between June 16th and July 11th, 2001.

ISA was estimated on June 16th, 2001 using the method developed by Weng et al. (2009) (Fig. 3d). Through this method, impervious surface was calculated based on the relationship between the reflectance of two endmembers (high- and low-albedo) and the reflectance of the impervious areas. By examining the relationships between impervious surfaces and four endmembers, it is found that impervious surfaces were located on or near the line connecting the low- and high-albedo endmembers in the feature space. An estimation procedure was thus developed based on this relationship by adding the fractions of high- and low-albedo endmembers.

Energy use from commercial and residential buildings was estimated using a building energy simulation method (right panel of Fig. 2). In this method, the simulation of building energy use was driven by the typical meteorological year data. Base on data availability noon time of June 15th, 2002 (Saturday) was chosen to represent building energy use for the typical weekend during the summer time to be comparable to the remotely sensed anthropologic heat discharge. The major data used in the building energy modeling includes a GIS database of building footprints, the County Assessor's parcel database, and the building height data. A local GIS database of building footprints was collected and used to retrieve the floor area of each building. The County Assessor's parcel database was a Microsoft Access based dataset. It was used to retrieve the building type and age and to link with the GIS building footprint. Building heights were estimated from a remote sensingbased digital surface model and a digital elevation model and used to calculate floor numbers for each building.

\section{Methodology}

\subsection{Estimation of anthropogenic heat discharge}

In this study, anthropogenic heat discharge was estimated based on a surface energy balance modeling method (Kato and
Yamaguchi, 2005; Kato et al., 2008; Oke, 1988; Xu et al., 2008). The method is illustrated in the left panel of Fig. 2. The surface energy balance due to surface properties and anthropogenic heating in the near-surface in an urban area can be expressed as follows:

$Q_{f}=H+L E+G-R_{n}$

where $Q_{f}$ is the anthropogenic heat discharge $\left(\mathrm{W} \mathrm{m}^{-2}\right), H$ is the sensible heat $\left(\mathrm{W} \mathrm{m}^{-2}\right), L E$ is the latent heat flux $\left(\mathrm{W} \mathrm{m}^{-2}\right)$, and $G$ is the ground heat flux $\left(\mathrm{W} \mathrm{m}^{-2}\right)$, and $R_{n}$ is the net radiation $\left(\mathrm{W} \mathrm{m}^{-2}\right)$. Based on the surface energy balance model, anthropogenic heat discharge $Q_{f}$ can be estimated as the residual term.

In the energy balance equation, net radiation $\left(R_{n}\right)$ is the sum of short and long wave radiation at the land surface (Kato and Yamaguchi, 2005). It is calculated as

$R_{n}=(1-\alpha) R_{S}+\varepsilon_{a} \varepsilon R_{d}-\varepsilon R_{u}$

where $R_{S}$ is the shortwave radiation $\left(\mathrm{W} \mathrm{m}^{-2}\right)$ which is retrieved from the meteorological data. $\alpha$ is the surface albedo which is derived from the remote sensing data, and the creation of $30 \mathrm{~m}$ spatial resolution albedo data is discussed in the data section. $\varepsilon$ is the surface emissivity, and it is determined based on land type from NLCD land cover data (Snyder et al., 1998). $\varepsilon_{a}$ is the atmospheric emissivity, and it is estimated using an empirical equation used by Kato and Yamaguchi (2005)

$\varepsilon_{a}=1.24\left(\frac{e_{a}}{T_{a}}\right)^{1 / 7}$

where $T_{a}$ is the atmospheric temperature (K) from meteorological data, and $e_{a}$ is the atmospheric water vapor pressure (hPa), which is estimated using the method by Allen et al. (1998)

$e_{a}=\frac{R H_{\text {mean }}}{100} \frac{e^{\circ}\left(T_{\min }\right)+e^{\circ}\left(T_{\max }\right)}{2}$

where $e^{\circ}\left(T_{\min }\right)$ is the saturation vapor pressure at daily minimum temperature $(\mathrm{hPa}), e^{\circ}\left(T_{\max }\right)$ is the saturation vapor pressure at daily maximum temperature $(\mathrm{hPa})$, and $R H_{\text {mean }}$ is the mean relative humidity (\%).

$R_{d}$ and $R_{u}$ used to calculate net radiation $\left(R_{n}\right)$ are the downward and upward blackbody radiation $\left(\mathrm{W} \mathrm{m}^{-2}\right)$, and they are calculated using the following equations (Xu et al., 2008)

$R_{d}=\sigma T_{a}^{4}$

$R_{u}=\sigma T_{s}^{4}$

where $\sigma$ is the Stefan-Boltzmann constant $\left(5.67 \mathrm{E}-08 \mathrm{~W} \mathrm{~m}^{-2} \mathrm{~K}^{-4}\right)$, and $T_{s}$ is the surface kinetic temperature (K). The process to derive the surface temperature was discussed in the data section.

Sensible heat flux $(H)$ is estimated based on the following equation (Allen et al., 1998; Kato and Yamaguchi, 2005; Kato et al., 2008; Xu et al., 2008)

$H=\rho C_{p} \frac{T_{o}-T_{a}}{r_{a}}$

where $\rho$ is the air density $\left(\mathrm{kg} \mathrm{m}^{-3}\right), C_{p}$ is the specific heat of air at constant pressure $\left(\mathrm{J} \mathrm{kg}^{-1} \mathrm{~K}^{-1}\right)$, and $T_{o}$ is the surface aerodynamic temperature. As $T_{o}$ is difficult to obtain, remote sensing derived surface temperature was used to approach $T_{o}$ (Kato et al., 2008). $r_{a}$ $\left(\mathrm{s} \mathrm{m}^{-1}\right)$ is the aerodynamic resistance which is calculated using the following simple relation (Allen et al., 1998)

$r_{a}=\frac{\ln \left(\frac{z_{m}-d}{z_{0 m}}\right) \ln \left(\frac{z_{h}-d}{z_{0 h}}\right)}{k^{2} u_{z}}$

where $z_{m}$ is the height of wind measurements $(m), z_{h}$ is the height of humidity measurements $(m), d$ is the zero plane displacement height $(m), z_{0 \mathrm{~m}}$ is the roughness length governing momentum 
transfer $(m), z_{0 \mathrm{~h}}$ is the roughness length governing transfer of heat and vapor $(m), k$ is the von Karman's constant $(0.4)$, and $u_{z}$ is the wind speed $\left(\mathrm{m} \mathrm{s}^{-1}\right)$ at height $z$ from the meteorological data.

Latent heat flux $(L E)$ is estimated using the following equation (Kato and Yamaguchi, 2005)

$L E=\rho C_{P} \frac{e_{s}-e_{a}}{\gamma\left(r_{a}+r_{s}\right)}$

where $e_{s}$ is the saturation vapor pressure $(\mathrm{hPa}), \gamma$ is the psychrometric constant $\left(\mathrm{hPa} \mathrm{K}^{-1}\right)$, and $r_{s}$ is the stomatal resistance $\left(\mathrm{s} \mathrm{m}^{-1}\right)$ which is estimated based on land type from the NLCD land cover data (Kato et al., 2008).

Ground heat flux $(G)$ is estimated using the following empirical equation by Kato and Yamaguchi (2005)

$G=C_{g} R_{n}$

where $C_{g}$ is a fixed coefficient based on the NLCD land cover type and season (Kato and Yamaguchi, 2005).

\subsection{Estimation of energy use from residential and commercial buildings}

Energy use from residential and commercial buildings was estimated using a building energy modeling method, which is illustrated in the right panel of Fig. 2. The method for $\mathrm{CO}_{2}$ emissions quantification developed by Zhou and Gurney (2010), in which on-site fossil-fuel $\mathrm{CO}_{2}$ emissions from residential and commercial buildings were quantified by downscaling the county-level commercial and residential fossil fuel $\mathrm{CO}_{2}$ emissions, was modified and extended. Using the modified method energy use from residential and commercial buildings was estimated for each building. First, a building typology was developed to define the building types for residential and commercial building stock in Indianapolis. A total of 30 building prototypes, 22 commercial and eight residential, were defined based on the building type, size, and age with the help of the Marion County Assessor's parcel database.

Second, hourly building Energy Use Intensity (EUI) - the energy used per unit floor area - was simulated using the Quick Energy Simulation Tool (eQUEST) for each building prototype (US Department of Energy, 2009). The major parameters used in eQUEST simulation including building shell characteristics (e.g., $R$ value), internal load (e.g., lighting) and Heating, Ventilating, and Air Conditioning system characteristics were derived from Huang et al. for the North Central US census region (Huang et al., 1991). Indianapolis was specified as the location in eQUEST simulation to retrieve the typical weather information for this region. The EUIs and the ratio of the non-electric to electric EUI values from the eQUEST simulation were calibrated using the US Department of Energy's Energy Information Administration data for the East North Central Census Division from its residential energy consumption survey and commercial building energy consumption survey (US Energy Information Administration, 2001; US Energy Information Administration, 2003).

Finally, energy use in each building was estimated from the calibrated non-electric and electric EUIs, building area and number of floors as follows:

$E_{\text {building }(i)}=\left(\mathrm{EUI}_{t, \text { building }(i)}^{\text {ele }}+\mathrm{EUI}_{t, \text { building }(i)}^{\text {nonele }}\right) A_{\text {building }(i)} \mathrm{NF}_{\text {building }(i)}$

where $\mathrm{EUI}_{t, \mathrm{building}(i)}^{\text {ele }}$ is the electric energy use intensity of building type $t$ for building $i$, EUI t,building $(i)^{\text {nonele }}$ is the non-electric energy use intensity of building type $t$ for building $i, A_{\text {building(i) }}$ is the footprint area of building $i$ (which was retrieved from a local GIS database of building footprints), and $\mathrm{NF}_{\text {building(i) }}$ is the number of floors for building $i$ which was estimated based on building height calculated from a remote sensing-based digital surface model and a digital elevation model using the method by Zhou and Gurney (2010). With the combination of building area from GIS footprint data, building type from the Assessor's parcel data, floor numbers from building height data, and electric and non-electric EUIs for building prototypes, energy use in all residential and commercial buildings was estimated in the study area.

\section{Results}

\subsection{Anthropogenic heat discharge}

The anthropogenic heat discharge in the study area at noon time on June 16th, 2001 was estimated using the energy balance method. To reduce the uncertainties in the evaluation of anthropogenic heat discharge, especially in less developed areas, ISA data were used to exclude pixels with the ISA less than $25 \%$. The result of anthropogenic heat discharge estimation is shown in Fig. 4. The result shows the spatial pattern and magnitude of anthropogenic heat discharge in the City of Indianapolis in a typical summer time. The anthropogenic heat discharge ranges from 0 to $400 \mathrm{~W} \mathrm{~m}^{-2}$, with a mean value of $32 \mathrm{~W} \mathrm{~m}^{-2}$. The high anthropogenic heat discharge occurs in the dense residential and commercial areas such as the center of the city and the residential areas in the northwest corner of the city. The township of Center has the highest anthropogenic heat discharge of $78 \mathrm{~W} \mathrm{~m}^{-2}$ as it has high density of commercial buildings while the Franklin township with large rural areas observes the lowest value. There are negative values in the anthropogenic heat discharge estimation, although it theoretically should be greater than $0 \mathrm{~W} \mathrm{~m}^{-2}$. These negative values are regarded as estimation errors, and were set to $0 \mathrm{~W} \mathrm{~m}^{-2}$ in the final result.

\subsection{Building energy use}

Using the building energy modeling approach, the energy use from residential and commercial buildings in each building at noon time on June 15th, 2002 was estimated in the study area. The spatial distribution of the energy use from residential and commercial buildings at a re-sampled $90 \mathrm{~m}$ spatial resolution is illustrated in

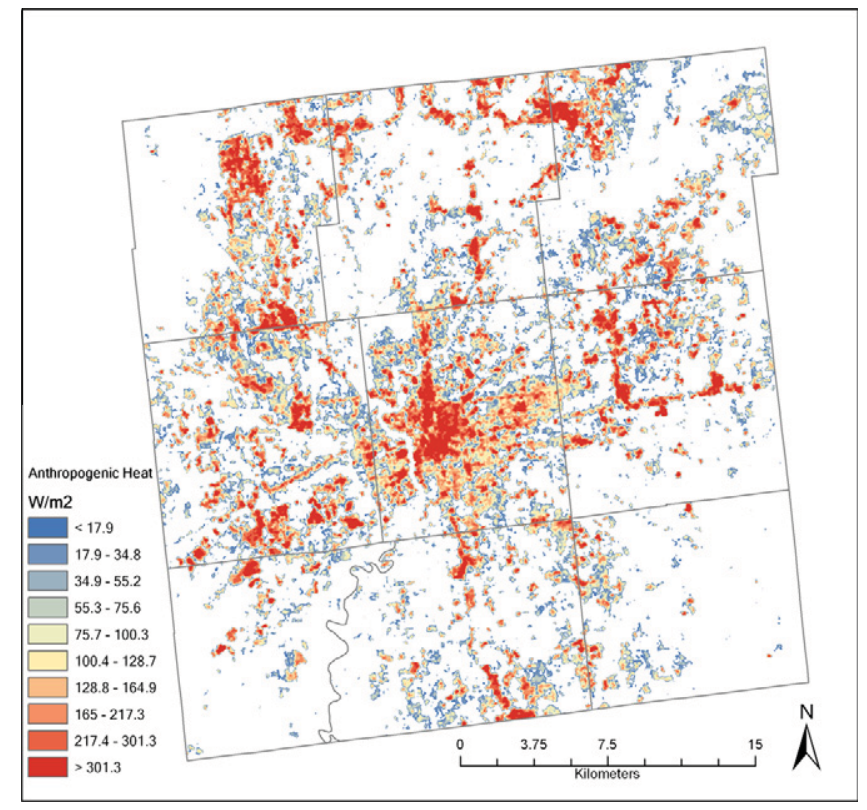

Fig. 4. The spatial distribution of anthropogenic heat discharge. 
Fig. 5. To be consistent with the anthropogenic heat discharge estimation, the building energy use was examined with the exclusion of pixels with the ISA less than $25 \%$. The energy use from residential and commercial buildings ranges from 0 to $85 \mathrm{~W} \mathrm{~m}^{-2}$ with a mean value of $5.5 \mathrm{~W} \mathrm{~m}^{-2}$. The spatial variation of building energy use is mainly determined by building density, height and type. The spatial pattern shows that the highest building energy use occurs at the city center, and that the township of Center possesses the highest energy use of $36 \mathrm{~W} \mathrm{~m}^{-2}$. The building energy use is also high in dense residential areas associated with suburban development in the outer ring of Highway 465 in Indianapolis as shown in Fig. 5.

\subsection{Spatial relationship, uncertainty and scale effect}

Although energy use from residential and commercial buildings represents only one component of anthropogenic heat discharge, it shows an obvious consistency in terms of spatial distribution with remote sensing-derived anthropogenic heat discharge. Visual comparison between anthropogenic heat discharge (Fig. 4) and building energy use (Fig. 5) shows that they both are higher in the dense residential and commercial areas and lower in the rural areas. In order to evaluate the quantitative relationship two variables were compared at pixel levels as well as at the census block level. First, the building energy use and anthropogenic heat discharge data were re-sampled to a variety of spatial resolutions of $90 \mathrm{~m}, 180 \mathrm{~m}, 270 \mathrm{~m}, 360 \mathrm{~m}$ and $450 \mathrm{~m}$. Furthermore, the pixels with $0.5 \%$ of the ranked building energy use in the both ends, which are considered as outliers, were excluded in the analysis. The relationship between these two variables across these scales and the additional census block level is shown in Fig. 6a-f. The result indicates that the correlation between building energy use and anthropogenic heat discharge is statistically significant at all spatial scales $(p<0.001)$, and that the relationship between two variables varies with scales. The explained variance of building energy use by anthropogenic heat discharge increases with the decreasing spatial resolution.

A potential application of this study is to reduce the uncertainty in urban energy balance study through independent estimation of

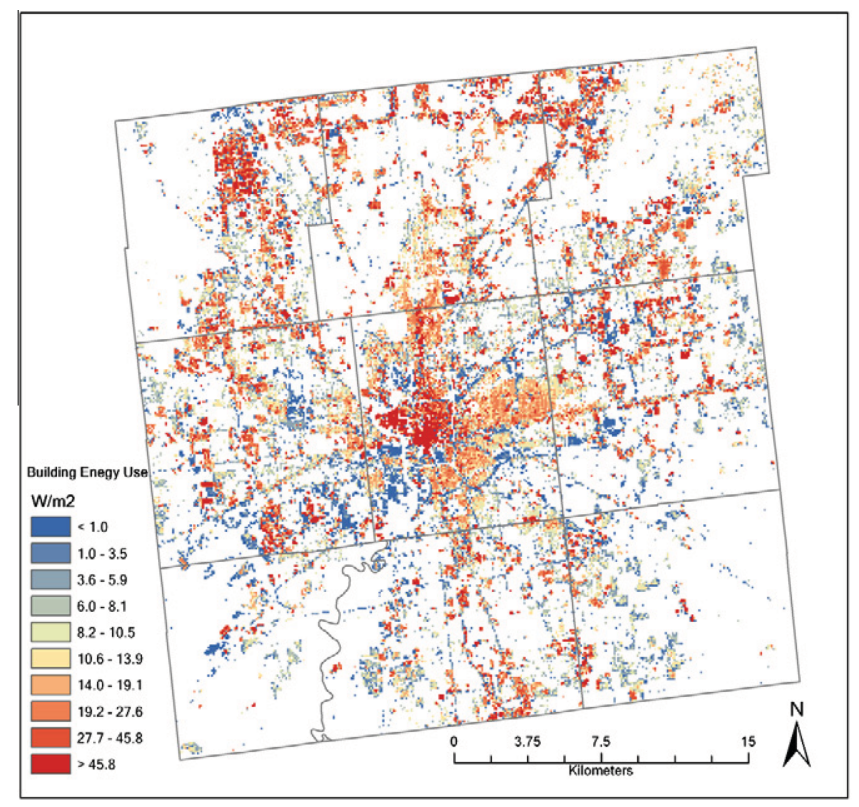

Fig. 5. The spatial distribution of energy use from commercial and residential buildings. anthropogenic heat discharge and building energy use. It is worth noting that there are uncertainties in both datasets of anthropogenic heat discharge and building energy use which might contribute to the discrepancy between these two variables to be discussed in the next paragraph. The uncertainty in the estimated anthropogenic heat discharge mainly came from each component in the surface energy balance. The input parameters of meteorological data, land cover, land surface temperature, and albedo may introduce the uncertainty towards the final estimation of anthropogenic heat discharge. The uncertainty in the estimated building energy use mainly came from EUIs using eQUEST simulation and building height extracted from a digital surface and a digital elevation model. The uncertainty analysis of fossil-fuel $\mathrm{CO}_{2}$ emissions which is based on non-electric building energy use can be found in the study by Zhou and Gurney (2010) using a Monte Carlo approach. The uncertainty of non-electric energy use in each town is approximately within $10 \%$ of the total energy use.

The discrepancy between building energy use and anthropogenic heat discharge is caused by several factors. First, anthropogenic heat discharge includes not only energy use from residential and commercial buildings, but also other sources such as energy use from industrial buildings and transportation. The quantitative relationship confirms that building energy use accounts for part of anthropogenic heat discharge. Second, energy use from residential and commercial buildings was estimated based on the typical weather information at noon time on June 15th, 2002 while the anthropogenic heat discharge was estimated at noon time on June 16th, 2001. The different dates of the input data may have introduced inconsistency between two variables. Third, as only low resolution meteorological data such as wind speed and air temperature used in the energy balance method, the spatial variation of impact from meteorological factors was not considered due to data limitation. Finally, image registration of data used in the estimation of two variables may also bring in uncertainties in the investigation of the relationship. It is one of the reasons that the correlation between anthropogenic heat discharge and building energy use varies with the spatial resolution. With the decreasing spatial resolution, the error of the spatial registration between two images decreases. Therefore the correlation between building energy use and anthropogenic heat discharge increases as indicated by Fig. 6 .

\section{Implications}

There are still challenges to obtaining accurate estimation of each component of heat flux in the urban energy balance such as the ground heat flux. Accurate estimation of anthropogenic heat discharge will help to better understand the urban energy balance and separate the contribution of anthropogenic heat discharge from that of ground heat flux. By combining with energy use from other sources such as industrial buildings and transportation, the spatially-resolved energy use from residential and commercial buildings will improve the estimation of anthropogenic heat discharge, and therefore, help to reduce the uncertainties in the study of urban energy balance.

The relationship between building energy use and anthropogenic heat discharge indicates that anthropogenic heat discharge may be able to serve as a spatial distribution proxy for the spatially-resolved energy use in an urban landscape. In addition, because of the relationship between energy use and fossil-fuel $\mathrm{CO}_{2}$ emissions, anthropogenic heat discharge, which is relatively easy to obtain with the help of remotely sensed data, provides the potential to develop spatially-resolved fossil-fuel $\mathrm{CO}_{2}$ emissions from building sectors with additional considerations. Together with point source and mobile emissions, the spatially-resolved fossilfuel $\mathrm{CO}_{2}$ emissions dataset will help to improve the scientific 

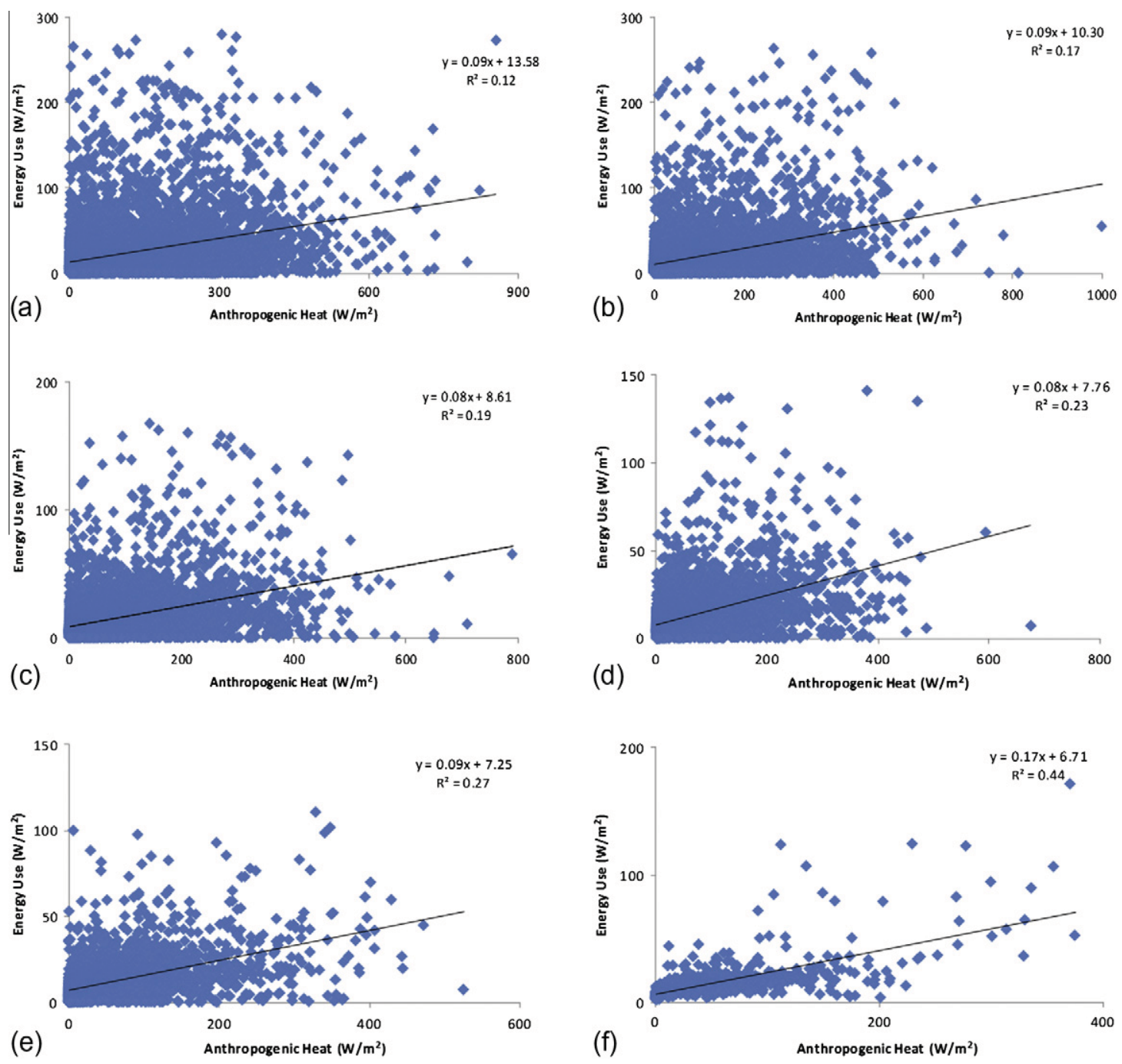

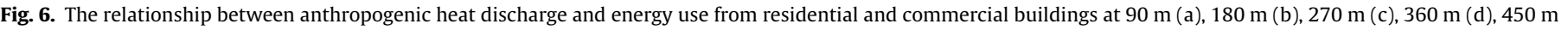
(e) spatial resolution, and the US census block level (f).

understanding of the contribution of human induced emissions to atmospheric concentration through transport modeling in the urban domain.

\section{Conclusions}

In this study, the anthropogenic heat discharge and energy use from residential and commercial buildings were estimated using two independent methods simultaneously in the City of Indianapolis in the summer time. The anthropogenic heat discharge was estimated using a remote sensing method, while the energy use from residential and commercial buildings was estimated with a GIS-based simulation method. The mean anthropogenic heat discharge is $32 \mathrm{~W} \mathrm{~m}^{-2}$ while the energy use from residential and commercial buildings is $5.5 \mathrm{~W} \mathrm{~m}^{-2}$. The visual comparison and quantitative analysis show consistency between anthropogenic heat discharge and building energy use in terms of the spatial pattern and magnitude. The spatial relationship between anthropogenic heat discharge and building energy use varies with the spatial scales, and the explained variation of the building energy use by anthropogenic heat discharge increases with the decreasing spatial resolution. The results of the quantitative relationship also confirm that the energy use from residential and commercial buildings represents only partial anthropogenic heat discharge which includes additional components of energy use such as those from industrial buildings and transportation.

The spatial consistency between anthropogenic heat discharge and energy use from residential and commercial buildings indicates that remotely sensed anthropogenic heat discharge may be able to serve as a spatial proxy to derive the spatial pattern of energy use, and even fossil-fuel $\mathrm{CO}_{2}$ emissions with consideration of additional factors. As the spatial relationship between building energy use and anthropogenic heat discharge varies with spatial scales, appropriate spatial resolution should be identified in future studies to aid the development of spatially-resolved energy use datasets.

The independent estimation of building energy use and anthropogenic heat discharge will also help to improve the estimation of other heat fluxes and the understanding of energy balance in the urban areas. In order to reduce the uncertainties in the study of urban energy balance, further studies of energy use from other human activities, especially industrial activities and transportation, should be combined with the estimation of energy use from residential and commercial buildings to obtain a more complete picture of human energy use in an urban domain. 


\section{References}

Allen, R.G., Pereira, L.S., Raes, D., Smith, M., 1998. Crop Evapotranspiration Guidelines for Computing Crop Water Requirements. Food and Agriculture Organization, Rome, Italy.

Bastiaanssen, W.G.M., Menenti, M., Feddes, R.A., Holtslag, A.A.M., 1998a. A remote sensing surface energy balance algorithm for land (SEBAL). Part 1: Formulation. Journal of Hydrology 212-213, 198-212.

Bastiaanssen, W.G.M., Pelgrum, H., Wang, J., Ma, Y., Moreno, J.F., Roerink, G.J., van der Wal, T., 1998b. A remote sensing surface energy balance algorithm for land (SEBAL). Part 2: Validation. Journal of Hydrology 212-213, 213-229.

Belan, B., Pelymskii, O., Uzhegova, N., 2009. Study of the anthropogenic component of urban heat balance. Atmospheric and Oceanic Optics 22 (4), 441-445.

French, A.N., Jacob, F., Anderson, M.C., Kustas, W.P., Timmermans, W., Gieske, A., Su, Z., Su, H., McCabe, M.F., Li, F., Prueger, J., Brunsell, N., 2005. Surface energy fluxes with the advanced spaceborne thermal emission and reflection radiometer (ASTER) at the Iowa 2002 SMACEX site (USA). Remote Sensing of Environment 99 (1-2), 55-65.

Gillespie, A., Rokugawa, S., Hook, S., Matsunaga, T., Kahle, A., 1999. Temperature/ emissivity separation algorithm theoretical basis document (version 2.4), <http://eospso.gsfc.nasa.gov/eos_homepage/for_scientists/atbd/docs/ASTER/ atbd-ast-03.pdf $>$ (accessed 14.8.2011).

Heiple, S., Sailor, D.J., 2008. Using building energy simulation and geospatial modeling techniques to determine high resolution building sector energy consumption profiles. Energy and Buildings 40 (8), 1426-1436.

Homer, C., Huang, C., Yang, L., Wylie, B., Coan, M., 2004. Development of a 2001 National Land-Cover Database for the United States. Photogrammetric Engineering and Remote Sensing 70 (7), 829-840.

Huang, Y.J., Akbari, H., Rainer, L., Ritschard, R., 1991. 481 Prototypical Commercial Buildings for 20 Urban Market Areas. Lawrence Berkeley Laboratory, Berkeley, CA, USA.

Ichinose, T., Shimodozono, K., Hanaki, K., 1999. Impact of anthropogenic heat on urban climate in Tokyo. Atmospheric Environment 33 (24-25), 3897-3909.

Kato, S., Yamaguchi, Y., 2005. Analysis of urban heat-island effect using ASTER and ETM+ data: separation of anthropogenic heat discharge and natural heat radiation from sensible heat flux. Remote Sensing of Environment 99 (1-2), 4454.

Kato, S., Yamaguchi, Y., Liu, C.-C., Sun, C.-Y., 2008. Surface heat balance analysis of Tainan City on March 6, 2001 using ASTER and Formosat-2 data. Sensors 8 (9), 6026-6044.

Klysik, K., 1996. Spatial and seasonal distribution of anthropogenic heat emissions in Lodz, Poland. Atmospheric Environment 30 (20), 3397-3404.

Lee, S.H., Song, C.K., Baik, J.J., Park, S.U., 2009. Estimation of anthropogenic heat emission in the Gyeong-In region of Korea. Theoretical and Applied Climatology 96 (3), 291-303.

Masek, J.G., Vermote, E.f., Saleous, N., Wolfe, R., Hall, F.G., Huemmrich, F., Gao, F., Kutler, J., Lim, T.K., 2006. A Land surface reflectance data set for North America, 1990-2000. Geoscience and Remote Sensing Letters 3 (1), 68-72.

Masson, V., Grimmond, C.S.B., Oke, T.R., 2002. Evaluation of the town energy balance (TEB) scheme with direct measurements from dry districts in two cities. Journal of Applied Meteorology 41 (10), 1011-1026.

National Weather Service, 2002. Climatological normals for the period 1971-2000, <www.crh.noaa.gov/ind/print_localdata.php?loc=txtdat\&data=climatenormals.txt> (accessed 15.8.2011).

Oke, T.R., 1988. The urban energy balance. Progress in Physical Geography 12 (4), 471-508.

Oke, T.R., Spronken-Smith, R.A., Jáuregui, E., Grimmond, C.S.B., 1999. The energy balance of central Mexico City during the dry season. Atmospheric Environment 33 (24-25), 3919-3930.
Pigeon, G., Legain, D., Durand, P., Masson, V., 2007. Anthropogenic heat release in an old European agglomeration (Toulouse, France). International Journal of Climatology 27 (14), 1969-1981.

Pigeon, G., Moscicki, M.A., Voogt, J.A., Masson, V., 2008. Simulation of fall and winter surface energy balance over a dense urban area using the TEB scheme. Meteorology and Atmospheric Physics 102 (3), 159-171.

Sailor, D.J., 2011. A review of methods for estimating anthropogenic heat and moisture emissions in the urban environment. International Journal of Climatology 31, 189-199 (Special Issue).

Sailor, D.J., Lu, L., 2004. A top-down methodology for developing diurnal and seasonal anthropogenic heating profiles for urban areas. Atmospheric Environment 38 (17), 2737-2748.

Schaaf, C.B., Gao, F., Strahler, A.H., Lucht, W., Li, X.W., Tsang, T., Strugnell, N.C., Zhang, X.Y., Jin, Y.F., Muller, J.P., Lewis, P., Barnsley, M., Hobson, P., Disney, M., Roberts, G., Dunderdale, M., Doll, C., D’entremont, R.P., Hu, B.X., Liang, S.L., Privette, J.L., Roy, D., 2002. First operational BRDF albedo nadir reflectance products from MODIS. Remote Sensing of Environment 83 (1-2), 135-148.

Schmugge, T.J., Kustas, W.P., Humes, K.S., 1998. Monitoring land surface fluxes using ASTER observations. IEEE Transactions on Geoscience and Remote Sensing 36 (5), 1421-1430.

Shuai, Y., Masek, J.G., Gao, F., Schaaf, C.B., 2011. An algorithm for the retrieval of 30$\mathrm{m}$ snow-free albedo from Landsat surface reflectance and MODIS BRDF. Remote Sensing of Environment 115 (9), 2204-2216.

Shuai, Y., Schaaf, C.B., Strahler, A.H., Liu, J., Jiao, Z., 2008. Quality assessment of BRDF/albedo retrievals in MODIS operational system. Geophysical Research Letter 35, L05407.

Snyder, W.C., Wan, Z., Zhang, Y., Feng, Y.-Z., 1998. Classification-based emissivity for land surface temperature measurement from space. International Journal of Remote Sensing 19 (14), 2753-2774.

Taha, H., 1997. Urban climates and heat islands: albedo, evapotranspiration, and anthropogenic heat. Energy and Buildings 25 (2), 99-103.

US Department of Energy, 2009. eQUEST, <http://www.doe2.com> (accessed 15.8.2011).

US Energy Information Administration, 2001. Residential Energy Consumption Survey. Energy Information Administration, Washington, DC, USA.

US Energy Information Administration, 2003. Commercial Building Energy Consumption Survey. Energy Information Administration, Washington, DC, USA.

US Census Bureau, 2009. Annual Estimates of the Resident Population for Incorporated Places over 100,000, <http://www.census.gov/popest/cities/SUBEST2008.html> (accessed 15.8.2011).

van der Kwast, J., Timmermans, W., Gieske, A., Su, Z., Olioso, A., Jia, L., Elbers, J., Karssenberg, D., de Jong, S., 2009. Evaluation of the surface energy balance system (SEBS) applied to ASTER imagery with flux-measurements at the SPARC 2004 site (Barrax, Spain). Hydrology and Earth System Sciences Discussion 6 (1), 1165-1196.

Voogt, J.A., Oke, T.R., 2003. Thermal remote sensing of urban climates. Remote Sensing of Environment 86 (3), 370-384.

Weng, Q., Hu, X., 2008. Medium spatial resolution satellite imagery for estimating and mapping. Urban Impervious Surfaces Using LSMA and ANN 46 (8), 2397-2406.

Weng, Q., Hu, X., Liu, H., 2009. Estimating impervious surfaces using linear spectral mixture analysis with multitemporal ASTER images. International Journal of Remote Sensing 30 (18), 4807-4830.

Xu, W., Wooster, M.J., Grimmond, C.S.B., 2008. Modelling of urban sensible heat flux at multiple spatial scales: a demonstration using airborne hyperspectral imagery of Shanghai and a temperature-emissivity separation approach. Remote Sensing of Environment 112 (9), 3493-3510.

Zhou, Y., Gurney, K., 2010. A new methodology for quantifying on-site residential and commercial fossil fuel $\mathrm{CO} 2$ emissions at the building spatial scale and hourly time scale. Carbon Management 1 (1), 45-56. 